\title{
Changing Pattern of Post-infectious Glomerulonephritis: A Study in South-Western Region of Bangladesh
}

\author{
Muhammed Arshad Ul Azim*', Md. Motiur Rahaman², Kamruzzaman Md. Zahir ${ }^{3}$, \\ Md. Obaidul Hauque ${ }^{4}$, Md. Abdul Wadud ${ }^{5}$, Mafia Akter ${ }^{6}$
}

\begin{abstract}
Introduction: In developing countries like Bangladesh, post-infectious glomerulonephritis (PIGN) is the common form of acute glomerulonephritis having its changing pattern over recent decades. The aim of the study was to analyze the clinical profile of PIGN in local scenario. Materials and Methods: This cross-sectional study was conducted at Shaheed Sheikh Abu Naser Specialized Hospital, Khulna during period from 2017 to 2019. A total of 67 cases of PIGN were identified on the basis of clinical features, laboratory parameters with recent history of infection. The patients' records were reviewed with respect to clinical data. Patients with reduced complement level were included. Result: The age range of the patients was between 2 and 55 years with male predominance. The study revealed that 32.8\% of patients had a recent history of sore throat, $31.3 \%$ of patients had a history of skin infection and rest $35 \%$ had a history of fever. Moreover, during presentation $68 \%$ of patients had hypertension and $37 \%$ of patient had renal impairment. In this study, majority of patients (53\%) presented with one plus to two plus proteinuria and the rest of the patients $(37 \%)$ presented with three plus proteinuria on dipstick. After 2 weeks of follow up, the presence of hematuria found in 58 patients out of 67, proteinuria found in 14 patients out of 61 and renal impairment found in 5 patients out of 25. Conclusion: PIGN has been changing with respect to age, proteinuria and renal function. To follow-up periodically and reduction in overcrowding of the patients, would be one of the superior suggestions to reduce the spread of infectious diseases in our country.
\end{abstract}

Keywords: Post-infectious glomerulonephritis (PIGN), Proteinuria, Renal Impairment, Infection.

Number of Tables: 02; Number of Figure: 01; Number of References: 22; Number of Correspondence: 03.

*1. Corresponding Author:

Dr. Muhammed Arshad UI Azim

Assistant Professor, Department of Nephrology

Shaheed Sheikh Abu Naser Specialized Hospital

Khulna, Bangladesh.

Email: arshadulazim@gmail.com

Phone no: +8801742141516.

2. Dr. Md. Motiur Rahaman

Department of Gastroenterology

BIRDEM General Hospital, Dhaka, Bangladesh.

3. Dr. Kamruzzaman Md. Zahir

Assistant Professor

Department of Respiratory Medicine

Sher-E-Bangla Medical College, Barishal. Bangladesh.

4. Dr. Md. Obaidul Hauque

Assistant Professor, Department of Paediatrics

Sheikh Hasina Medical College, Habiganj, Bangladesh.

5. Dr. Md. Abdul Wadud

Resident Physician

Shaheed Sheikh Abu Naser Specialized Hospital, Khulna, Bangladesh.

6. Dr. Mafia Akter

Senior Medical Officer, Department of Neurology BIRDEM General Hospital, Dhaka, Bangladesh.

\section{Introduction}

Post-infectious glomerulonephritis (PIGN) is one of the oldest recognized renal diseases worldwide ${ }^{1,2}$. PIGN is the commonest form of acute glomerulonephritis (AGN) in developing countries ${ }^{3,4}$. Despite declining incidence of PIGN in many developed countries, there is still a significant numbers of patients in developing countries. PIGN is mainly diseases of poverty, because overcrowding and poor hygiene are prevailing. PIGN is an immune-mediated form of glomerulonephritis (GN) that typically develops 1-3 weeks after an episode of acute bacterial infection of upper respiratory tract or $\operatorname{skin}^{5,6}$. Previously it was commonly caused by group A beta hemolytic streptococci. But with the time, the causative organisms have become changed with Staphylococcus and other gram negative organism's also $^{1}$. PIGN is characterized by abrupt onset of hematuria, edema, hypertension, proteinuria, oliguria and diminished renal function ${ }^{7}$. It is considered a benign transient condition. Though the incidence of PIGN has lowered in the past few decades, reports of epidemics and clusters of cases continue to appear worldwide. It is affecting more children than adults. It most commonly affects in children between 5-12 years and it is uncommon before the age of 3 years ${ }^{3}$. PIGN accounts for about $21 \%$ of children admitted to hospital with acute renal failure in developing countries ${ }^{8}$. The characteristics of the disease has changed over recent decades ${ }^{9}$.

The goal of this study is to review the clinicopathological spectrum of the disease in a major tertiary care renal referral hospital. But there is paucity of data in Bangladesh. Hence, the aim of this study was to analyze clinical profile of PIGN in local scenario.

\section{Materials and Methods}

The hospital based cross-sectional study was conducted in Shaheed 
Sheikh Abu Naser Specialized Hospital, Khulna which located in south western region of Bangladesh, during two years period from 2017 to 2019. In this study, the terminology PIGN is used instead of post-streptococcal glomerulonephritis (PSGN). In the absence of highly sensitive diagnostic modality in resource limited countries, the definitive infective etiology could not be established in many patients presenting with acute glomerulonephritis (AGN). Since there were no classic diagnostic criteria for PIGN, the treating physician usually made a final diagnosis of PIGN on the basis of clinical features and available biochemical parameters and excluding other types of glomerulonephritis whenever necessary.

Sixty seven cases of post-infectious glomerulonephritis were identified according to clinical features (edema, hematuria, hypertension and oliguria), laboratory parameters with a recent history of infection. The patients' records were reviewed with respect to clinical data including age, sex, skin or throat infection, blood pressure, laboratory, and clinical course. Blood pressure values and definitions were based on the fourth task force report on the diagnosis, evaluation, and treatment of high blood pressure in children and adolescence ${ }^{10}$. The laboratory parameters included urinalysis, serum creatinine and complement levels. Along with the relevant clinical feature, patients with reduced complement level were included. Proteinuria was tested by dipstick. The result were recorded as negative, trace, $1+(30 \mathrm{mg} / \mathrm{dL}), 2+(100$ $\mathrm{mg} / \mathrm{dL}), 3+(300 \mathrm{mg} / \mathrm{dL})$ and $4+(2000 \mathrm{mg} / \mathrm{dL})^{11}$. The data was analyzed descriptively for frequencies and percentage values. The tables as well as graphs were used to present the results.

\section{Results}

A total of 67 records of patients diagnosed with PIGN were included in this study. The age range of the participant patients was between 2 and 55 years with mean age of 16.4 years as shown in Table I.

Table-I: Variation of the age group of different patients.

\begin{tabular}{lcc}
\hline Age Range & Number of Patients & Participant Percentage \\
\hline $0-4$ & 2 & 2.98 \\
$5-9$ & 16 & 23.8 \\
$10-14$ & 26 & 38.8 \\
$>15$ & 23 & 34.3 \\
\hline
\end{tabular}

Out of 67 patients, 43 patients are male and 24 are female with male to female ratio of 1.7:1.

Recent history of sore throat was present in $32.8 \%$ of patients, history of skin infection was in $31.3 \%$ of patients and history of fever was present in $35 \%$ of patients.

At presentation $68 \%$ of patients had hypertension.

During presentation, serum creatinine more than $1.2 \mathrm{mg} / \mathrm{dl}$ was in 25 patients and rest of the patient had serum creatinine less than $1.2 \mathrm{mg} / \mathrm{dl}$. That means $37 \%$ patient had renal impairment at presentation. Those patients presented with renal impairment were older than 10 years of age.
In this study proteinuria was evaluated with dipstick. During presentation, $4.48 \%$ of patients did not have any proteinuria. Another $4.48 \%$ of patients had trace proteinuria during initial presentation. And rest of the patients presented with different categories of proteinuria as shown in figure 1 .

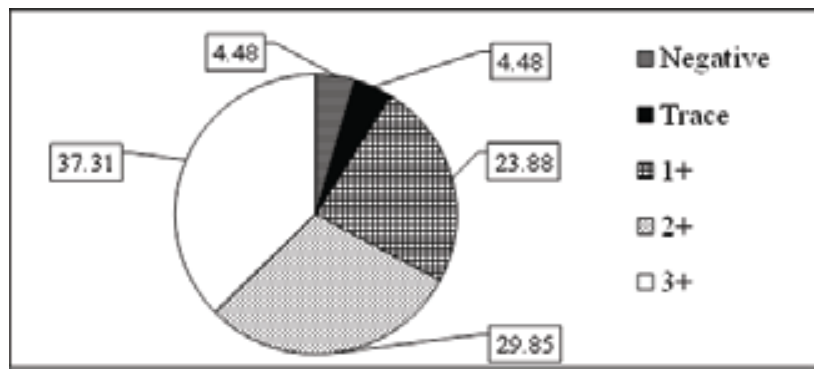

Figure-1: Dipstick test for protein at presentation

Among the patients with $3+$ proteinuria $(\mathrm{N}-25)$ only one patient was in age group 0-4, six patients were in age group 5-9. And rests of the patients were more than 10 years of age as shown in table II.

Table-II: Age distribution 3+ proteinuria patients ( $\mathrm{N}-25)$ :

\begin{tabular}{lcc}
\hline Age Range & Number of Patients & Participant Percentage \\
\hline $0-4$ & 1 & 4 \\
$5-9$ & 6 & 24 \\
$10-14$ & 9 & 36 \\
$>15$ & 9 & 36 \\
\hline
\end{tabular}

After 2 weeks of follow up:

Hematuria ( $\mathrm{RBC} \geq 5 / \mathrm{hpf}$ ) was present in 58 patients.

Proteinuria was in 14 patients

Serum creatinine more than 1.2 was present in 5 patients out of 25 patients. All of them were adult.

\section{Discussion}

This study revealed that among 67 patients with PIGN, 62 $\%$ patients were the school -going having age range of 5-15 years. Similar results were reported by other studies ${ }^{12,13,14}$.

As this hospital is only nephrology service providing hospital in this part of the country, so all patients were included in this study.

In this study showed more cases of PIGN in male individuals which were comparable to other studies ${ }^{3,15,16}$.

In this study, the history of sore throat was present in $32.8 \%$ and history of skin infection was present in $31 \%$. A study from Nepal showed that history of sore throat and skin infection in $20 \%$ and in $31 \%$ respectively ${ }^{3}$. A recent study from Chennai, India showed history of upper respiratory tract infection in $25 \%$ and history of skin infection in $11.7 \%$ that was more similar to our study ${ }^{17}$.

In this study, 68\% patients had hypertension during presentation.

A study by Gebreyesus et al. found hypertension in $64.1 \%$ of PIGN patient at the onset ${ }^{18}$. The initial clinical presentation was similar to that described in the literature, with hypertension ${ }^{9,19,20}$. 
In this present study, $37 \%$ patient had renal impairment at presentation. Those patients presented with renal impairment were older than 10 years of age. A study of PIGN on children showed $31.7 \%$ of the patients had renal impairment at presentation ${ }^{3}$.

Another study of PIGN on adult showed $60 \%$ of the patients had renal impairment during presentation ${ }^{17}$. The result of this study was concordant with the result of both of the two studies, because this study included both children and adult patients.

In this study, 53\% patients had mild to moderate proteinuria and $37 \%$ patients had nephrotic range proteinuria. In case of adult patient, G Nataranjan. et al showed $60 \%$ had nephrotic range proteinuri ${ }^{17}$. The occurrence of nephrotic range proteinuria were 14-60\% described in the different literature?

Follow up: In this study, follow up after two weeks $86 \%$ patients had hematuria. A study from Bangladesh Khoybar MA et al, showed $24 \%$ patients had hematuria during discharge. In their study, period of hospitalization was 1 to 36 days (mean 12.98 days). This was may be the explanation of less number of patients with hamaturia in their study ${ }^{13}$.

In our study follow up after two weeks, $21 \%$ patients had proteinuria. A study in Bangladesh showed similar result ${ }^{13}$.

In this study 25 patients had renal impairment at presentation and after two weeks 5 patients had renal impairment. That means $7 \%$ patients had renal impairment after two weeks. Most of the studies reported excellent prognosis for children with $\mathrm{PIGN}^{21,22}$. But studies in adults reported less favorable outcome ${ }^{17}$.

\section{Conclusion}

Since Bangladesh is a one of the developing countries, Post-infectious glomerulonephritis is still common in both children and adult population. PIGN has been changing in respect to age, proteinuria and renal function. Renal impairment was not uncommon in PIGN patients during initial presentation. In this study, adult patients had more amount of proteinuria than children. During follow up, persistence of hematuria was common. It is important to follow-up periodically all the patients especially in adult. Prevention of epidemics of post-infectious glomerulonephritis requires an active community participation in controlling the infection. Improvement in housing, particularly reduction in overcrowding, will hinder the spread of infectious diseases in our country.

Conflict of Interest: None.

\section{Acknowledgement}

My gratitude goes to Shaheed Sheikh Abu Naser Specialized hospital and Department of nephrology for the provision of such a golden opportunity to conduct the study.

\section{References}

1. Siddappa S, Kowsalya1 R, Mythri KM. A review of postinfectious glomerulonephritis cases from a tertiary care renal referral center in South India. International Journal of Health \& Allied Sciences. 2013; 2: 264-269.

https://doi.org/10.4103/2278-344X.126745

2. Lou C, Tang Z, Chen D, Liu Z. Long term prognosis for Chinese adultpatients with acute postinfectious glomerulonephritis. Clin Nephrol. 2011; 76:186 94.

https://doi.org/10.5414/CN107001

PMid:21888855

3. Shah, G. Post-infective glomerulonephritis in children: a hospital based study. Journal of Patan Academy of Health Sciences. 2017 Jun; 4(1): 26-31.

https://doi.org/10.3126/jpahs.v4i1.24664

4. Forfar, Arneils. Disorders of urogenital System, AGN. In: Text Book of Pediatric. 5th ed. Churchill Livingstone; 960-62.

5. Rammelkamp CH, Weaver RS. Acute glomerulonephritis: The significance of the variation in the incidence of the disease. J Clin Invest. 1953; 32: 346-58.

https://doi.org/10.1172/JCI102745

PMid:13052693 PMCid:PMC438348

6. Poon-King T, Mohammed I, Cox R. Recurrent epidemic nephritis in South Trinidad. N Engl J Med. 1967; 277: 728-33.

https://doi.org/10.1056/NEJM196710052771403

PMid:6042874

7. Roy R R, Laila K. Acute Post-Streptococcal Glomerulonephritis in Children - A review. Bangladesh J Child Health. 2014; 38(1): 33.

https://doi.org/10.3329/bjch.v38i1.20025

8. Singhal PC, Malik GH, Narayan G, Khan AS, Bhusnurmath S, Datta BN. Prognosis of post streptococcal glomerulonephritis: Chandigarh study. Ann Acad Med Singapore. 1982; 11: 3641.

9. Moroni G, Pozzi C, Quaglini S. Long-termprognosis of diffuse proliferative glomerulonephritis associated with infection in adults. Nephrol Dial Transplant. 2002; 17: 1204-11.

https://doi.org/10.1093/ndt/17.7.1204

PMid:12105242

10. The Fourth Task Force report on the Diagnosis, Evaluation, and Treatment of High Blood Pressure in Children and Adolescence. NIH Publication. No. 05-5267.1995; 96-3790.

11. Abitbol C, Zilueruelo G, Freundlich M. Quantitation of proteinuria with urinary protein creatinine ratios and random testing with dipstick in nephritic syndrome. J PediatrClin North Am.1997; 44: 1191-210.

12. Rodríguez-Iturbe B, Mezzano S. Acute Postinfectious Glomerulonephritis. In: Ellis D. Avner, William E. Harmon, Patrick Niaudet, Norishige Yoshikawa, editors. Pediatric Nephrology. 6th ed. 1:740-8.

13. Khoybar MA, Sultana S, Shaha AK, Anwar MH, 
Ashraful MI, Ruhul AS, et al. Immediate outcome of acute glomerulonephritis in children - experience in a tertiary level hospital. Bangladesh Journal of Medical Science. 2011 Oct; 10(4): 269-74.

https://doi.org/10.3329/bjms.v10i4.9499

14. Glassock RJ, Cohen Ah, Adler SG. Primary Glomerular Diseases. In: Brenner and Rector's The Kidney. 5th ed. Saunders. 2: 1392-1473.

15. Streeton CL, Hanna JN, Messer RD, Merianos A. An epidemic of acute post-streptococcal glomerulonephritis among aboriginal children. J Paediatr-child-Health. 1995; 31(3): 245-8.

https://doi.org/10.1111/j.1440-1754.1995.tb00795.x

PMid:7669388

16. Gopalakrishnan Natarajan. Follow-Up Study of Post-Infectious Glomerulonephritis in Adults: Analysis of Predictors of Poor Renal Outcome. Saudi J Kidney Dis Transpl. 2014; 25(6):1210-1216.

https://doi.org/10.4103/1319-2442.144254

PMid:25394437

17. Gebreyesus LG, Aregay AF, Gebrekidan KG, Alemayehu YH. Factors associated with treatment outcome of acute post streptococcal glomerulonephritis among patients less than 18 years in MekelleCity, Public Hospitals, North Ethiopia. BMC Res Notes. 2018; 11: 693. https://doi.org/10.1186/s13104-018-3794-7

PMid:30285899 PMCid:PMC6167782
18. Travis LB, Dodge WF, Beathard GA. Acute glomerulonephritis in children. A review of the natural history with emphasis on prognosis. Clin Nephrol. 1973; $1: 169-81$

19. Helal I, Kaaroud H, Goucha R, Ben Moussa F, BenMaiz $H$, Kheder A. The Pattern of histologically-proven acute post-infectious glomerulonephritis in Tunisian adults seen in 1976-2004. Arab J Nephrol Transplant. 2012; 2:93-6.

20. Montseny JJ, Meyrier A, Kleinknecht D, Callard P. The current spectrum of infectious glomerulonephritis. Experience with 76 patients and review of the literature. Medicine (Baltimore). 1995; 74: 63-73. 12.

https://doi.org/10.1097/00005792-199503000-00001

PMid:7891544

21. Kasahara T, Hukyakawa H, Okubo S. Prognosis of post-streptococcal glomerulonephritis (APSGN) is excellent in children, when adequately diagnosed. Pediatr Int. 2001; 43: 364-7.

https://doi.org/10.1046/j.1442-200X.2001.01410.x

PMid: 11472580

22. Rodriguez Iturbe B, Musser JM. The current state of poststreptococcal glomerulonephritis. J Am Soc Nephrol. 2008; 19:1855 64.

https://doi.org/10.1681/ASN.2008010092

PMid:18667731 